\title{
DPP-4 inhibitor
}

National Diabetes Information Clearinghouse (NDIC)

\section{Definitions}

Type 2 diabetes

Defined by National Diabetes Information Clearinghouse (NDIC)

Blood glucose

Defined by National Diabetes Information Clearinghouse (NDIC)

Insulin

Defined by National Diabetes Information Clearinghouse (NDIC)

Liver

Defined by National Diabetes Information Clearinghouse (NDIC)

\section{Source}

National Diabetes Information Clearinghouse (U.S.). (2009). The diabetes dictionary. [Bethesda, Md.]: U.S. Dept. of Health and Human Services, National Institutes of Health, National Institute of Diabetes and Digestive and Kidney Diseases,

National Diabetes Information Clearinghouse.

A class of oral medicine used to treat type 2 diabetes that lowers blood glucose by helping the body make more insulin when it's needed. This type of medicine also helps keep the liver from putting stored blood glucose into the blood.

(Generic name/Brand name: sitagliptin phosphate/Januvia.) 